\section{Some Theoretical Considerations About the Excited Singlet and Triplet States of Diformamide and N-Methyl Diformamide}

Julio Marañon and Oscar M. Sorarrain

Departamento de Física y Departamento de Química, Facultad de Ciencias Exactas, Universidad Nacional de La Plata, Calle 49 y 115, La Plata, República Argentina

$$
\begin{gathered}
\text { (Z. Naturforsch. } 32 \text { a, 103-104 [1977] ; } \\
\text { received August 28, 1976) }
\end{gathered}
$$

The molecules of diformamide and N-methyl diformamide are analysed using the CNDO-CI method. Several excited singlet and triplet states corresponding to the three possible conformers and charge distributions are discussed.

It has been shown experimentally that three planar conformers are possible for the molecule of diformamide ${ }^{1-6}$. They are given in Figure $1 . \mathrm{R}=\mathrm{H}$ corresponds to diformamide and $\mathrm{R}=\mathrm{CH}_{3}$ to N-methyl diformamide. Diformamide is interesting for biologists. Similar molecules, iso-electronic with diformamide have been calculated ab-initio ${ }^{7}$ and using CNDO-CI ${ }^{8}$. The results are in good agreement with the experimental data. We have calculated the electronic spectra of diformamide with the CNDO-CI method; moreover we have analysed the methyl radical as substituent and the charge densities for several excited singlet and triplet states. For the calculation we have used 30 configurations. This number was considered enough from previous papers ${ }^{9}$ and after several checks.

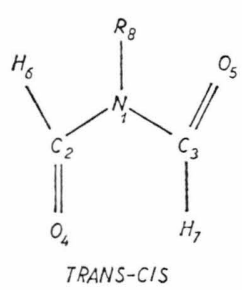

I

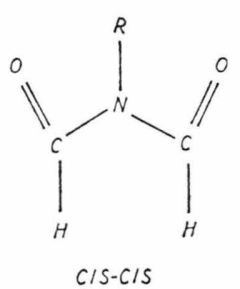

II

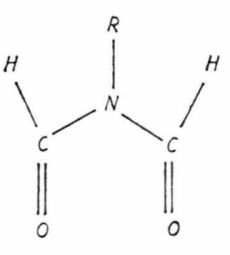

TRANS-TRANS

\section{Some Results}

In both molecules the orbital energies corresponding to the highest occupied molecular orbital (h.o.m.o.) are almost the same as for formimide $(\pi, 11.07 \mathrm{eV})^{7}$. The three highest occupied molecular orbitals correspond to lone pair orbitals of the three conformers of $\mathrm{N}$-methyl diformamide.

For both molecules the rotation about the amide bonds gives an inversion in one of the three highest occupied molecular orbitals corresponding to the $(\mathrm{C}-\mathrm{C})$ and $(\mathrm{T}-\mathrm{T})$ conformers [a lone pair $n(\sigma)$ changes to a lone pair $n(\pi)]$. The substitution of $\mathrm{H}$ in the $\mathrm{N}-\mathrm{H}$ bond with a methyl group gives clearly a localization on the $\mathrm{C}=\mathrm{O}$ bonds for the 2nd lowest unoccupied molecular orbital (2nd l.u.m.o.), see Table 1 .

For the excited singlet and triplet states we have chosen several transitions. They are discussed in the following.

The 3.35 and $3.56 \mathrm{eV}$ singlet transitions corresponding to the $(\mathrm{C}-\mathrm{T})$ conformer of diformamide are $n(\pi) \rightarrow \pi^{*}$ ones. There is also a strong line $n(\pi) \rightarrow \pi^{*}$ of $6.72 \mathrm{eV}$ (intensity 0.24 ) for the same conformer (the former ones are very weak). These results are in agreement with previous theoretical and experimental ones given by Del Bene ${ }^{8}$ for formaldehyde, formimide and formic acid. The mentioned 6.72 line corresponds to transitions between orbitals localized on the two oxygens and on the $\mathrm{C}=\mathrm{O}$ bonds. There is no intramolecular charge transfer. For both molecules in the $(\mathrm{T}-\mathrm{T})$ configuration the lowest transition is a ${ }^{1} \mathrm{~A}_{1}$ one.

Another interesting transition is the $6.57 \mathrm{eV}{ }^{1} \mathrm{~A}_{2}$ line (intensity 0.069 ) of diformamide. This level is complex $\left[\pi \rightarrow \sigma, \sigma \rightarrow \pi^{*}, n(\sigma) \rightarrow \sigma^{*},(\mathrm{~T}-\mathrm{T})\right]$.

For the $(\mathrm{C}-\mathrm{C})$ conformer of diformamide the first excited state has $3.42 \mathrm{eV}{ }^{1} \mathrm{~A}_{1}$. This transition is a $n(\sigma) \rightarrow \sigma^{*}$ one. For this conformer the strong transition of $6.78 \mathrm{eV}^{1} \mathrm{~A}_{2}$ (intensity 0.34) is also complex $\left[\pi \rightarrow \sigma^{*}, n(\sigma) \rightarrow \sigma^{*}\right]$.

For the molecule of N-methyl diformamide the first excited states are given by the following values:

\begin{tabular}{|c|c|c|}
\hline \multicolumn{3}{|c|}{ Diformamide } \\
\hline $\begin{array}{l}\text { Atoms } \\
\pi^{*} \mathrm{C}-\mathrm{T} 33 \% \mathrm{C}(2) \mathrm{O}(4), 55 \% \mathrm{C}(3) \mathrm{O}(5)\end{array}$ & $\begin{array}{l}\text { Atoms } \\
\mathrm{T}-\mathrm{T} \text { in all atoms }\end{array}$ & $\begin{array}{l}\text { Atoms } \\
\mathrm{C}-\mathrm{C} \text { in all atoms }\end{array}$ \\
\hline \multicolumn{3}{|c|}{$\mathrm{N}$-methyl diformamide } \\
\hline $\begin{array}{l}\text { Atoms } \\
\pi^{*} \mathrm{C}-\mathrm{T} \mathrm{C}(2) \mathrm{O}(4) 34 \%, \mathrm{C}(3) \mathrm{O}(5) 54 \%\end{array}$ & $\begin{array}{l}\text { Atoms } \\
\mathrm{T}-\mathrm{T} \mathrm{C}(2) \mathrm{O}(4) 44 \%, \mathrm{C}(3) \mathrm{O}(5) 44 \%\end{array}$ & $\begin{array}{l}\text { Atoms } \\
\mathrm{C}-\mathrm{C} \mathrm{C}(2) \mathrm{O}(4) 43 \%, \mathrm{C}(3) \mathrm{O}(5) 43 \%\end{array}$ \\
\hline
\end{tabular}

Table 1. Localization of the 2nd l.u.m.o. in both molecules; for the atoms see Figure 1.

$n(\pi)$ or $n(\sigma)$ lone pair m.o. 
$3.34 \mathrm{eV}$ for $(\mathrm{C}-\mathrm{T}) \quad\left[n(\sigma) \rightarrow \pi^{*}\right], 4.04 \mathrm{eV}$ for $(\mathrm{T}-\mathrm{T}) \quad\left[n(\sigma) \rightarrow \pi^{*}\right]$ and $4.98 \mathrm{eV}$ for $(\mathrm{C}-\mathrm{C})$ $\left[n(\pi) \rightarrow \sigma^{*}\right]$; according to the calculations these lines should be very weak. On the other hand, the $6.34 \mathrm{eV}$ line of the $(\mathrm{C}-\mathrm{T})$ and the $6.50 \mathrm{eV}{ }^{1} \mathrm{~A}_{2}$ line of the $(\mathrm{C}-\mathrm{C})$ conformer should be strong.

We have also calculated the charge distribution for the first excited state using the techniques given by Mishra et al. ${ }^{11-13}$ and by Langlet and Malrieux ${ }^{14}$. These results will be compared with those obtained by the CNDO-CI method.

For some transitions not reported in this paper there exists intramolecular charge transfer from the carbons to the nitrogen corresponding to the amide group. This result is in agreement with Del Bene's paper ${ }^{10}$ according to this author in the $\pi \rightarrow \pi^{*}$ or $n(\pi) \rightarrow \pi^{*}$ transitions the intramolecular charge transfer mainly involves the $\mathrm{C}, \mathrm{N}$ and $\mathrm{O}$ atoms.

1 W. E. Steinmetz, J. Amer. Chem. Soc. 95, 2777 [1973].

2 E. Noe and M. Raban, J. Amer. Chem. Soc. 95, 6118 [1973].

3 T. Oka and Y. Morino, J. Mol. Spectrosc. 37, 445 [1971].

4 T. Uno and K. Machida, Bull. Chem. Soc. Japan 36, 427 [1963].

5 Y. Kuroda, Y. Saito, K. Machida, and T. Uno, Spectro. Chim. Acta Part A 27, 1481 [1971].

6 A. L. Capparelli, J. Marañon, and O. M. Sorarrain, to be publish in Z. Phys. Chemie, Leipzig.

7 B. Mely and A. Pullman, Theor. Chim. Acta 13, 278 [1969].
Tables have been obtained giving the description of the molecular orbitals and their corresponding energies and symmetries, a set of excited singlet and triplet levels with their compositions derived from the configuration interactions, and the oscillator strengths for those singlets which should be observed. The charge densities on the carbons and nitrogens have also been calculated for the single excited singlets from the lst to the 8th excited level. The values are given for the three conformers. On request these informations will be made available to interested readers.

\section{Acknowledgements}

We are grateful to Consejo Nacional de Investigaciones de Argentina and O.E.A. for their help during the development of this paper.

8 J. Del Bene and H. H. Jaffe, J. Chem. Phys. 50, 1126 [1969].

9 J. W. Downing, J. Michl, P. Jörgensen, and E. W. Thul. strup, Theor. Chim. Acta 32, 203 [1974].

10 J. Del Bene and H. H. Jaffe, J. Chem. Phys. 49, 1221 [1968].

11 J. S. Yadav, P. C. Mishra, and D. K. Rai, Mol. Phys. 26, 193 [1973].

12 P. C. Mishra and D. K. Rai, Mol. Phys. 23, 631 [1972].

13 J. S. Yadav, P. C. Mishra, and D. K. Rai, Chem. Phys. Letters 31, 129 [1975].

14 J. Langlet and J. P. Malrieux, Theor. Chim. Acta 33, 307 [1974]. 